International Journal of Mechanical Engineering and Technology (IJMET)

Volume 12, Issue 3, March 2021, pp. 1-8. Article ID: IJMET_12_03_001

Available online at https://iaeme.com/Home/issue/IJMET?Volume=12\&Issue=3

ISSN Print: 0976-6340 and ISSN Online: 0976-6359

DOI: https://doi.org/10.34218/IJMET.12.3.2021.001

(C) IAEME Publication

Scopus Indexed

\title{
INVESTIGATIONS ON REDUCTION OF EMISSIONS IN SPARK IGNITION ENGINE
}

\author{
K.Laxmi \\ Department of Chemistry, Chaitanya Bharathi Institute of Technology, Gandipet, \\ Hyderabad, Telangana State, India \\ M. V.S. Murali Krishna* \\ Department of Mechanical Engineering, Chaitanya Bharathi Institute of Technology, \\ Gandipet, Hyderabad, Telangana State, India \\ *Corresponding Author
}

\begin{abstract}
In the scenario of abnormal increase of fuel prices in national and international market and increase of pollutants with fossil fuels, the search for alternative fuels has become important. Alcohols are good substitutes of gasoline, as they have high octane number and also they are renewable in nature. Investigations were carried out on a variable compression ratio spark ignition engine fitted with catalytic converter run with the gasohol (blend of $80 \%$ gasoline and $20 \%$ ethanol by volume) for reducing carbon monoxide (CO) and un-burnt hydro carbon emissions in the exhaust employing manganese ore as catalyst. The influence of parameters of void ratio, weight of the catalyst, speed and load on reduction of pollutants were determined. A microprocessor based analyzer is used for measurement of CO/UBHC emissions in the exhaust of the engine. The speed and the load were observed to have strong influence on reduction of $\mathrm{CO} / \mathrm{UBHC}$ in the exhaust. Air injection aided further reduction of $\mathrm{CO}$ and UBHC emissions. Gasohol decreased CO emissions considerably when compared to neat gasoline operation.
\end{abstract}

Keywords: Spark ignition engine- Alternative fuel-Ethanol- Emissions- Carbon monoxide-Un-burnt hydro carbons-Catalytic converter-Air injection.

Cite this Article: K. Laxmi and M. V. S. Murali Krishna, Investigations on Reduction of Emissions in Spark Ignition Engine, International Journal of Mechanical Engineering and Technology (IJMET), 12(3), 2021, pp.1-8. https://iaeme.com/Home/issue/IJMET?Volume=12\&Issue=3 


\section{INTRODUCTION}

Carbon monoxide emitted from the exhaust of spark ignition (SI) engine due to incomplete combustion is highly poisonous pollutant and this pollutant is considerably high during idling and peak load operation of the engine. [1]. Breathing of CO causes many health disorders. [23]. It also causes detrimental effects on animal and plant life besides environmental disorders. [4]. Hence Government of India has implemented stringent regulations for permissible CO levels in the exhaust of $2 / 4$ stroke petrol engines. Of many methods available for reduction of $\mathrm{CO}$, the one employing a catalytic converter is found to be more effective in reducing $\mathrm{CO}$ emissions [5-13]. UBHC emission, are formed due to combustion of fuel in crevice volume, as these areas are subjected to low temperatures Breathing of UBHC emissions cause respiratory diseases like tuberculosis and other health disorders. Hence control of these exhaust emissions is an important and immediate step. Manganese ore is used as catalyst in the investigations to reduce $\mathrm{CO} / \mathrm{UBHC}$ emissions, as it is abundantly available at low price. With the injection of air into the converter and increase of the temperature of the air, the oxidation of $\mathrm{CO} / \mathrm{UBHC}$ is expected to improve in the presence of catalyst. In the context of depletion of fossil fuels, increase of pollution levels with fossil fuels and increase of fuel consumption with the increase of vehicle density due to advancement of civilization, the search for alternative and renewable fuels has become pertinent. Ethanol is considered as an alternate fuel for use in spark ignition (SI) engine (Obert 1973) as the properties of ethanol are very close to those of gasoline. Octane number, which measures the ignition quality of SI engine fuels for ethanol, is higher in comparison with that of gasoline and hence no major modification in the engine is necessary if low quantities of ethanol blended with gasoline are used as a fuel in SI engine. Investigations were carried out with blends of gasoline and alcohols in conventional spark ignition engine and copper coated engine.[14-17]. They reported that alcohol blended gasoline improved performance and reduced pollutants of the engine.

There were systematic investigations on parametric variation of catalytic converter on reduction of pollutants of the engine using gasoline blended ethanol. The authors made an attempt to study the parametric variation of catalytic converter on reduction of pollutants of $\mathrm{CO}$ and UBHC emissions of variable compression ratio, variable speed spark ignition engine.

\section{MATERIALS AND METHODS}

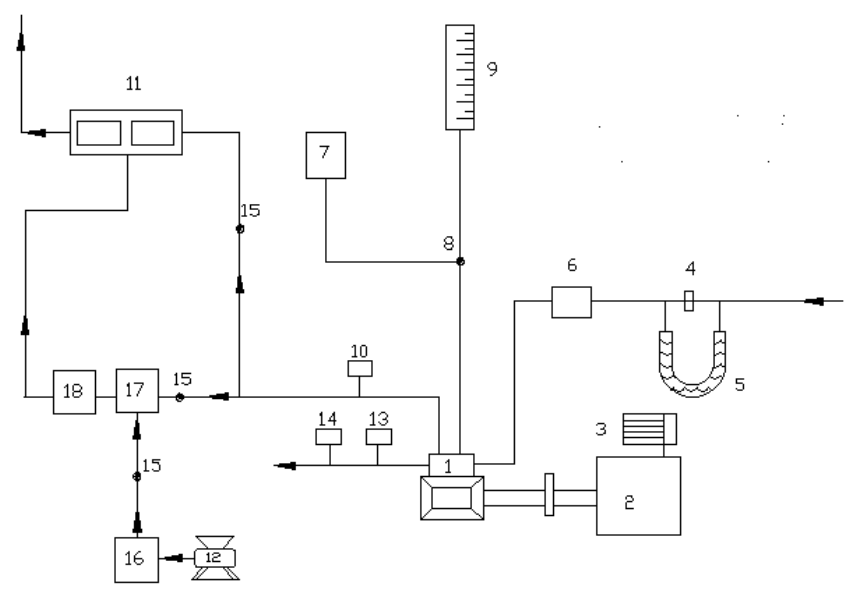

1. Engine, 2. Eddy current dynamometer, 3. Loading arrangement, 4. Orifice meter, 5. U-tube water monometer, 6. Air box, 7. Fuel tank, 8. Three-way valve, 9. Burette,10. Exhaust gas temperature indicator, $11 \mathrm{CO}$ analyzer, 12. Air compressor, 13. Outlet jacket water temperature indicator, 14. Outlet jacket water flow meter, 15. Directional valve, 16. Rotometer, 17. Air chamber and 18. Catalyst chamber

Figure 1 Schematic diagram of Experimental set up 
Figure. 1 shows the experimental set-up employed in the present investigation. It consists of a four- stroke, single-cylinder, water-cooled, petrol engine of brake power $3.0 \mathrm{~kW}$ at 3000 rpm. Engine was coupled to an eddy current dynamometer for measuring brake power of engine. There was a facility of varying compression ratio of the engine from 3 to 9 with change of the clearance volume with the adjustment of cylinder head, threaded to the cylinder of the engine. Engine speeds were varied from 2200 to $3000 \mathrm{rpm}$.

The bore and stroke of engine cylinder was $57 \mathrm{~mm}$ each. A catalytic converter, the details of which are presented in Fig. 2 is fitted to the exhaust pipe of the engine. Provision was made to inject a definite quantity of air into the converter. The converter was provided with catalyst of varying void ratios (void ratio is defined as the volume occupied by the catalyst to that of the catalytic chamber) ranging from 0.1 to 1 . The percentage of $\mathrm{CO} / \mathrm{UBHC}$ in the exhaust of the engine was measured with Netel Chromatograph $\mathrm{CO}$ analyzer. The sets of the exhaust gases were drawn at three locations one, immediately after the exhaust valve in the conventional engine, second, after the catalytic converter, and third with air injection into the converter. The quantity of air drawn from the compressor and injected into the converter was kept constant so that the backpressure do not increase and reverse flow was not created in the converter. There are three sets of the configurations used in the investigation for reducing CO/UBHC in the exhaust of SI engine. i) Set-A: Emissions from the engine without catalytic converter and without air injection. ii) Set-B: Emissions from the engine with catalytic converter and without air injection. iii) Set-C : missions from the engine with catalytic converter and with air injection.
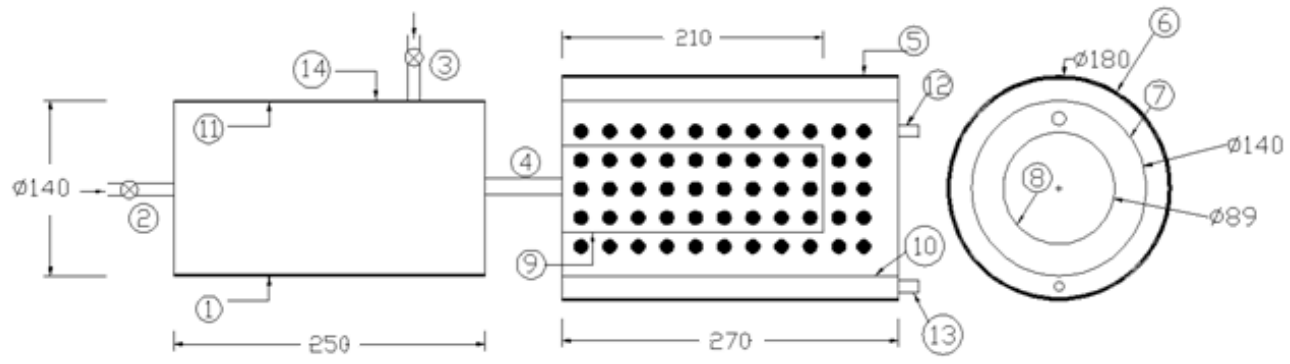

1.Air chamber, 2. Inlet for air chamber from the engine, 3. Inlet for air chamber from the compressor, 4. Outlet for air chamber, 5. Catalytic chamber, 6. Outer cylinder, 7. Intermediate-cylinder, 8. Inner-cylinder, 9. Inner sheet, 10. Intermediate sheet, 11. Outer sheet, 12. Outlet for exhaust gases, 13. Provision to deposit the catalyst, and, 14. Insulation.

Figure 2 Schematic diagram of catalytic conveter

\section{RESULTS AND DISCUSSION}

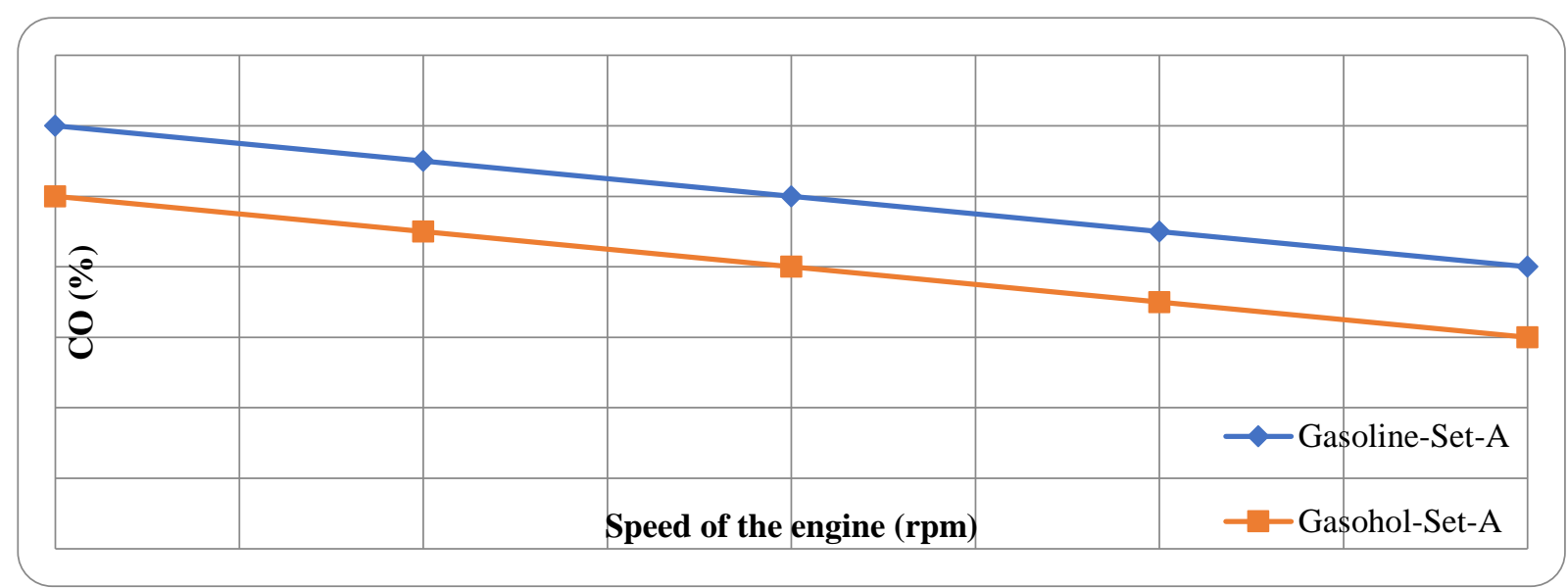

Figure 3 Variation of CO levels at full load with speed of the engine. 
Figure. 3 shows variation of $\mathrm{CO}$ levels at full load with speed of the engine at a compression ratio of 9:1.

As speed increased, CO levels at full load decreased with improved combustion because of turbulence. As speed increased, flame speed also increased leading to improve combustion. Hence the optimum speed of the engine was found to be $3000 \mathrm{rpm}$ for reduction of CO levels for both test fuels.

Figure. 4 shows the variation of $\mathrm{CO}$ levels at full load with the compression ratio of the engine at a speed of $3000 \mathrm{rpm}$.

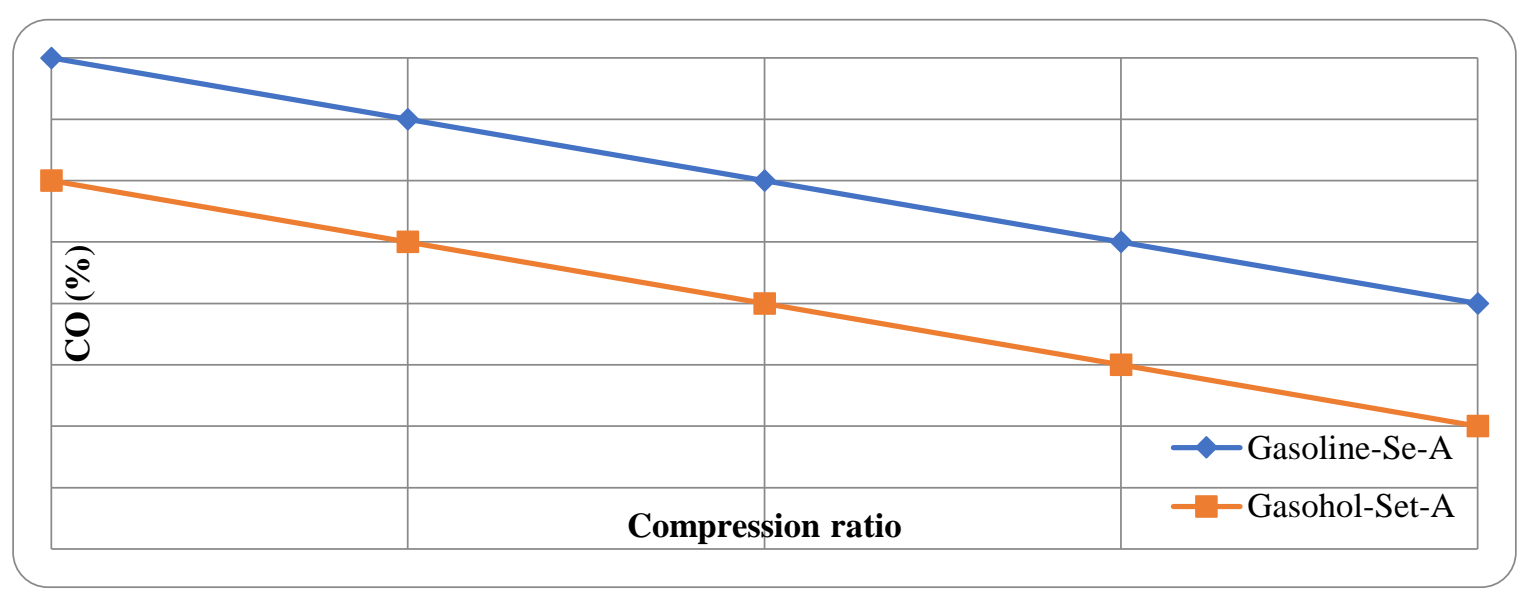

Figure 4 Variation of $\mathrm{CO}$ levels with compression ratio of the engine.

As compression ratio increased, $\mathrm{CO}$ levels at full load decreased due to improved combustion with compression ratio, as thermal efficiency increased with compression ratio. Therefore $\mathrm{CO}$ emissions decreased with an increase of compression ratio for both test fuels.

Fig.5 presents the variation of $\mathrm{CO}$ emissions at full load in the exhaust of the engine fuelled with gasoline with void ratio at a compression ratio of 9:1 and a speed of $3000 \mathrm{rpm}$. The compression ratio of 9:1 was found to be optimum as higher compression ratio gave higher brake thermal efficiency as per principles of thermodynamic [18]. The speed of $3000 \mathrm{rpm}$ was found to be optimum as higher speeds gave higher turbulence leading to increase flame speeds and hence thermal efficiency. It can be observed that the $\mathrm{CO}$ emissions reduced considerably with increasing void ratio (void ratio is the ratio of volume of the catalyst to the volume of the catalytic chamber) for test fuels. However, it is clearly established that beyond the void ratio of $0.7, \mathrm{CO}$ reduction is less for both cases due to reduction of surface/volume ratio and increase of backpressure on the engine.

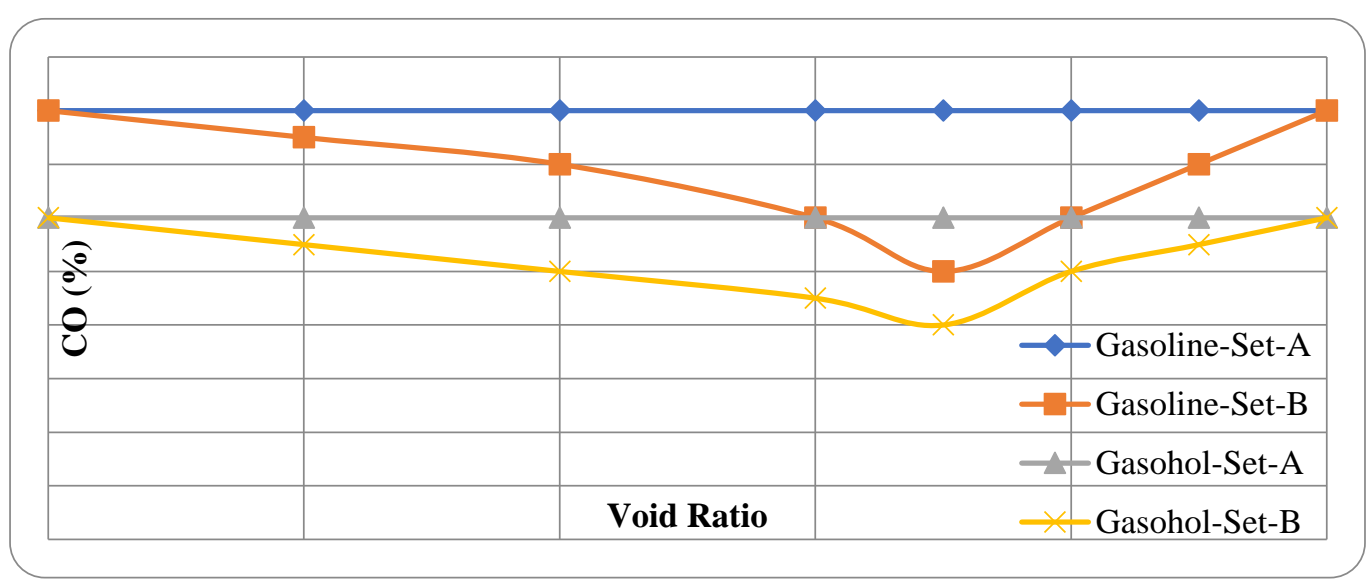

Figure 5 Variation of CO levels with void ratio 
At void ratio 0.7 , the reduction of $\mathrm{CO}$ is higher with gasohol when compared to that of gasoline as fuel-cracking reactions are eliminated with ethanol. Combustion of alcohol produced more water vapor than free carbon atoms as the molecular structure of ethanol contains lower value of the $\mathrm{C} / \mathrm{H}$ of 0.33 (where $\mathrm{C}$ represents number of carbon atoms while $\mathrm{H}$ represents number of hydrogen atoms in the composition of the fuel) against 0.44 of gasoline. Figure. 6 shows the variation of $\mathrm{CO}$ emissions at full load with the weight of the catalyst of manganese ore at a compression ratio of 9:1 and speed of $3000 \mathrm{rpm}$..

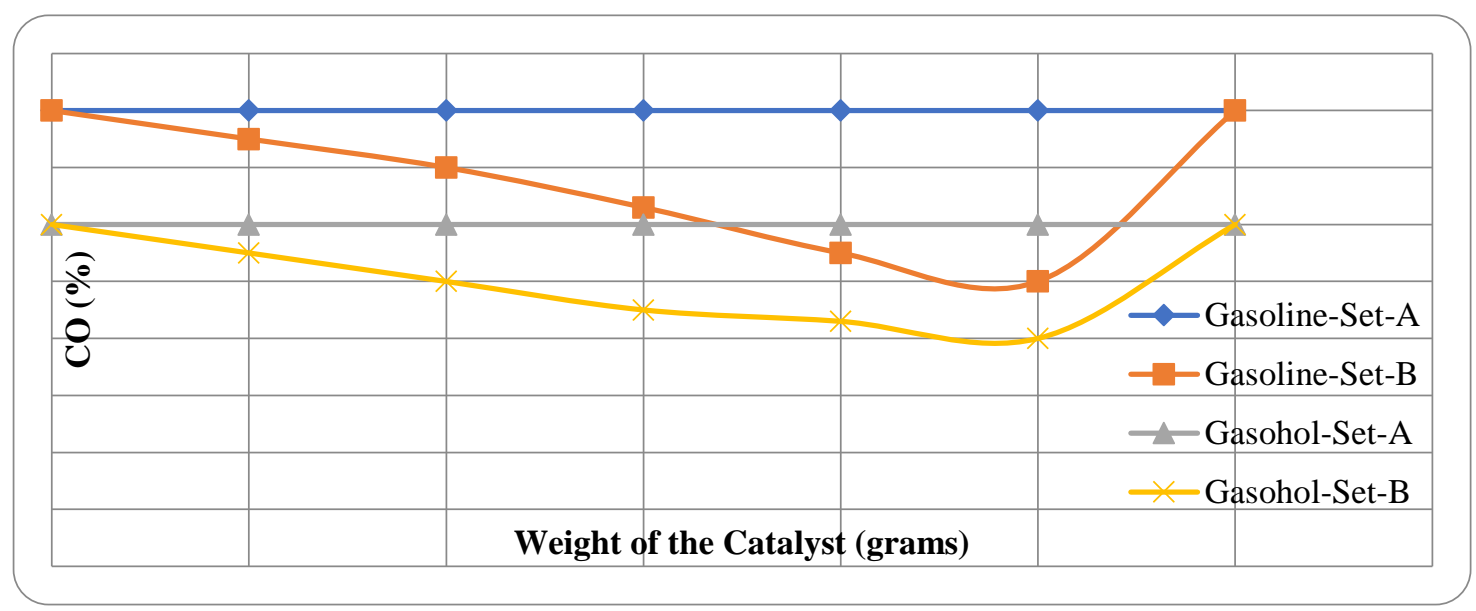

Figure 6 Variation of $\mathrm{CO}$ levels at full load with weight of the catalyst.

The weight of the catalyst is comparable parameter rather than void ratio of the catalyst, as it is easy to determine in the laboratory experiments. The weight of 500 grams was found to be optimum for both test fuels. Performance with weight more than 500 grams of the catalyst deteriorated with an increase of back pressure of the engine in reducing CO levels at full load operation. Surface to volume ratio decreased with weight more than 500 grams of the catalyst. Figure.7 shows the variation of $\mathrm{CO}$ emissions at full load with air flow rate of the catalytic converter at a compression ratio of 9:1 and speed of $3000 \mathrm{rpm}$.

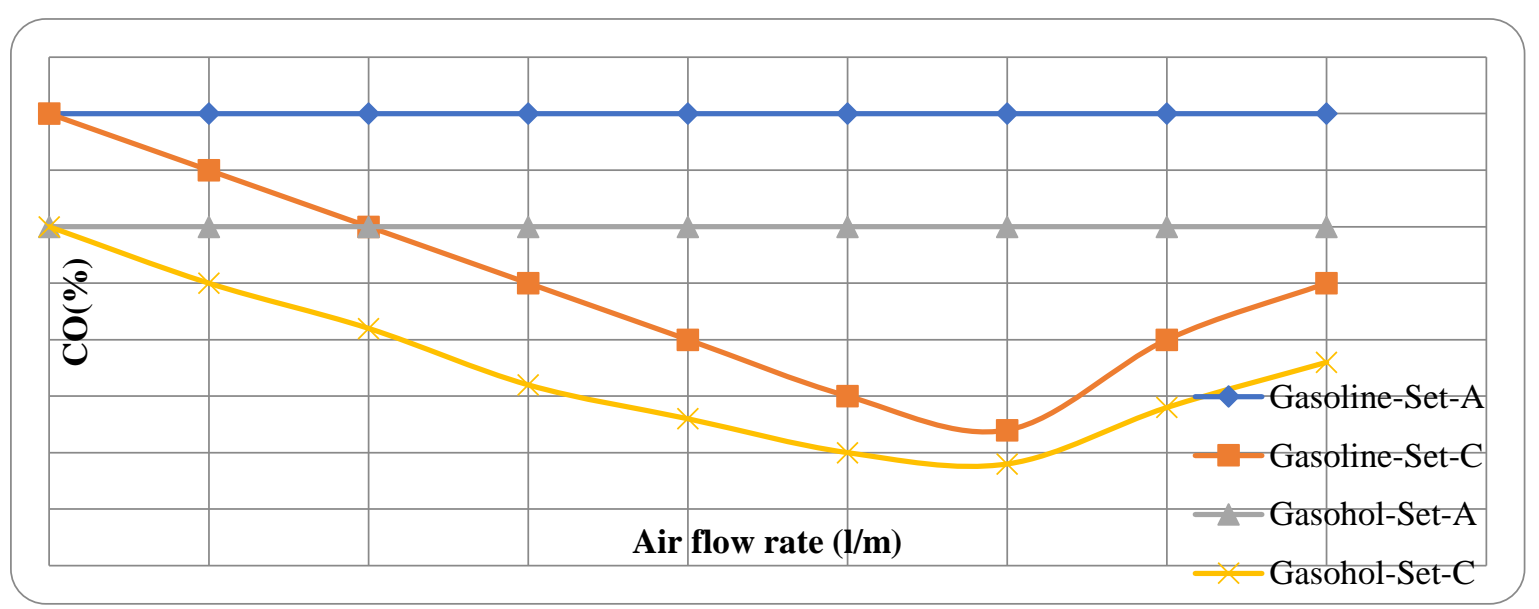

Figure 7 Variation of $\mathrm{CO}$ levels at full load with air flow rate of the catalytic converter.

There was a provision for air injection to the catalytic converter. The percentage of $\mathrm{CO}$ at full load was found to be lower when air quantity was $61 / \mathrm{m}$ for test fuels. Reaction rate with catalyst was lower, when quantity of air was more than optimum quantity. Reaction rate was lower when the quantity of the air was lower than optimum quantity.

Figure.8. shows the variation of $\mathrm{CO}$ emissions in the exhaust with brake mean effective pressure (BMEP) of the engine at a speed of $3000 \mathrm{rpm}$ with compression ratio of 9 and at a Set- 
A (without catalyst and air injection). CO emissions were observed to be increased at part load and at full load and decreased at nearly $80 \%$ of the full load. Nedunchezhian [Nedunchezhian et al. 2000] reported the same trend with spark ignition engine with gasoline on the emissions of CO. Gasohol decreased CO emissions considerably when compared to pure gasoline at all loads. Gasohol contained oxygen in fuel composition. Hence combustion improved with gasohol operation thus reducing $\mathrm{CO}$ emissions. Gasohol has high octane number causing improved combustion leading to reduce $\mathrm{CO}$ emissions at all loads.

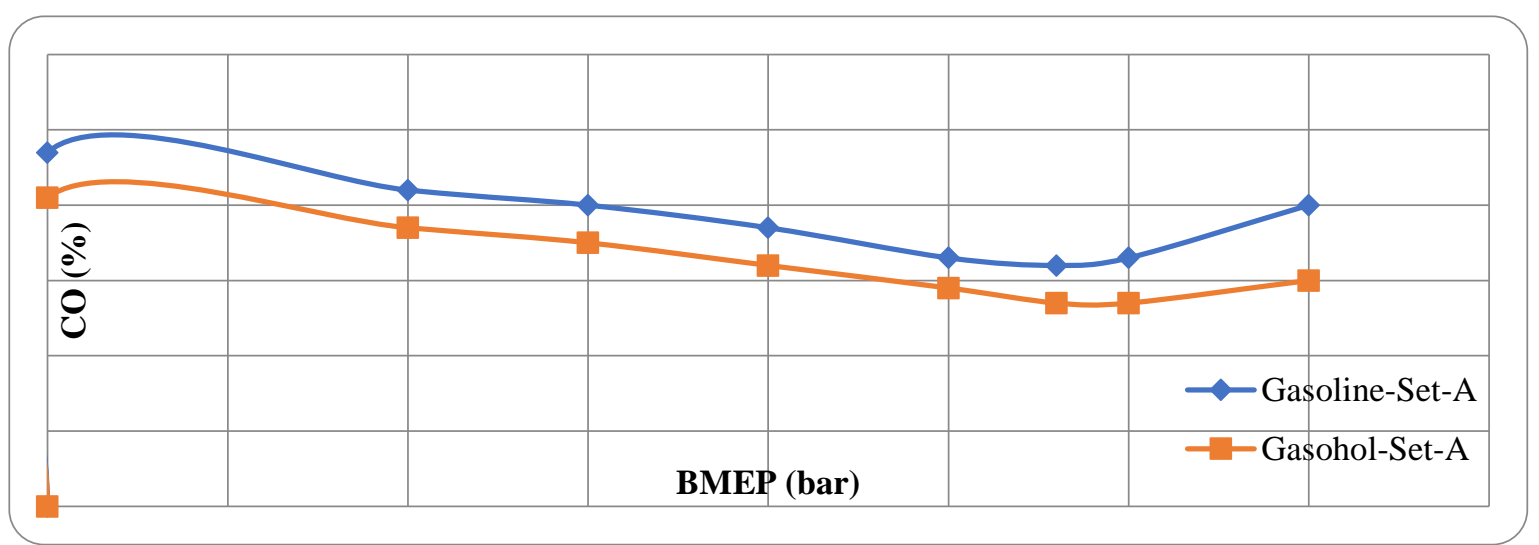

Figure 8 Variation of $\mathrm{CO}$ levels with brake mean effective pressure (BMEP) of the engine

Figure.9. shows the variation of UBHC emissions in the exhaust with brake mean effective pressure (BMEP) of the engine at a speed of $3000 \mathrm{rpm}$ with compression ratio of 9 and at a SetA (without catalyst and air injection).

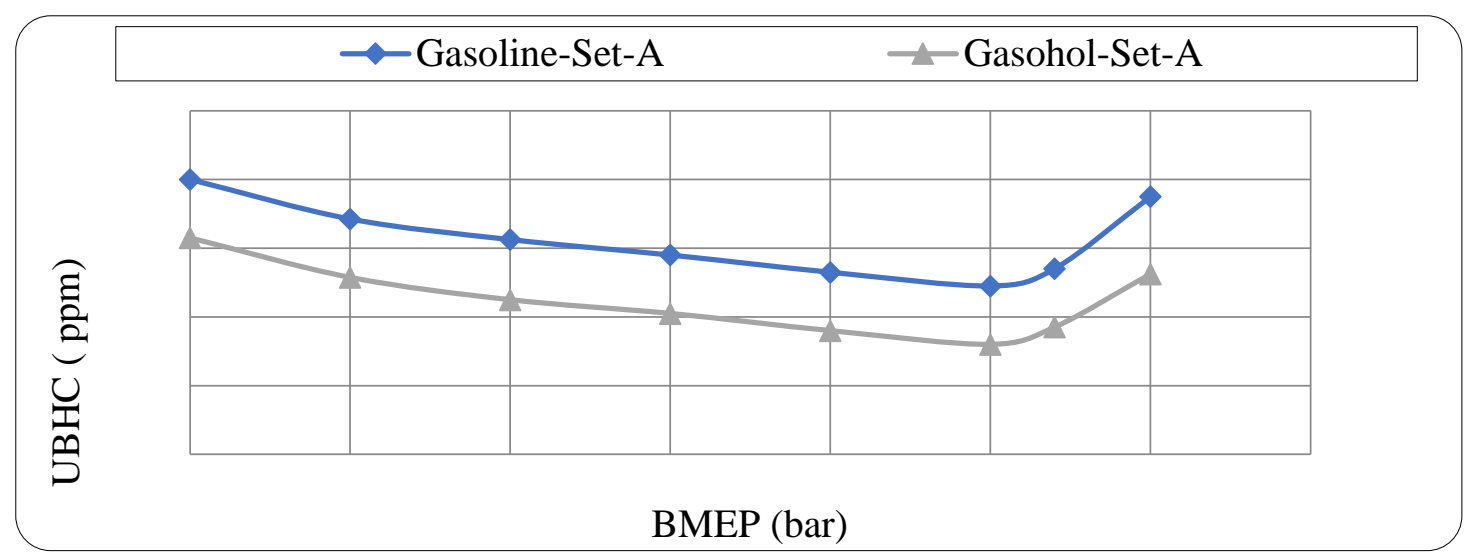

Figure 9 Variation of UBHC emissions with brake mean effective pressure (BMEP) of the engine.

UBHC emissions at full load followed similar trends with CO emissions at all loads. The presence of oxygen and improved octane number of gasohol improved combustion and thus reduced UBHC emissions at all loads in comparison with a neat gasoline. At part load, combustion temperatures are low, thus performance deteriorated thus producing higher UBHC emissions with both test fuels. At full load, sufficient oxygen was not available for combustion and the presence of fuel in crevice volume increased UBHC emissions, as crevice volume is subjected to lower temperatures because of the presence of coolant.

Table. 1 shows data of exhaust emissions at full load of single cylinder, four-stroke spark ignition engine at a compression ratio of 9:1 and a speed of $3000 \mathrm{rpm}$ at different operating condition of the catalytic converter-Set-A (without catalyst and without air injection, Set-B (with the catalyst and without air injection and Set-C (with catalyst and with air injection). The 
weight of the catalyst was maintained as 500 grams and air flow rate was employed as $6 \mathrm{l} / \mathrm{m}$.

Table 1 Data of exhaust emissions

\begin{tabular}{|c|c|c|c|c|}
\hline \multirow{2}{*}{ Set } & \multicolumn{2}{|c|}{ Pure Gasoline Operation } & \multicolumn{2}{c|}{ Gasohol } \\
\cline { 2 - 5 } & $\mathrm{CO}(\%)$ & UBHC $(\mathrm{ppm})$ & $\mathrm{CO}(\%)$ & UBHC $(\mathrm{ppm})$ \\
\hline Set-A & 4.0 & 750 & 3.0 & 510 \\
\hline Set-B & 2.5 & 400 & 2.0 & 275 \\
\hline Set-C & 1.2 & 150 & 0.9 & 100 \\
\hline
\end{tabular}

Set-B reduced exhaust emissions of CO and UBHC at full load by $40 \%$ when compared with Set-A condition. Improved oxidation reaction of catalyst, manganese ore reduced pollutants. Set-C reduced exhaust emissions of CO and UBHC at full load by $60 \%$ when compared with Set-A condition. Improved oxidation reaction of catalyst along with supply of oxygen reduced pollutants.

\section{CONCLUSIONS}

- Gasohol reduced exhaust emissions of CO and UBHC considerably when compared to neat gasoline operation.

- Compression ratio of 9:1 was proved to be optimum compression ratio.

- The speed of $3000 \mathrm{rpm}$ was found to be optimum in reducing pollutants.

- The void ratio of 0.7:1 was found to be optimum in reducing pollutants.

- The weight of catalyst of 500 grams was found to be optimum for reduction of pollutants.

- The air flow rate injected to the catalytic converter of $61 / \mathrm{m}$ was found to be optimum for reduction of pollutants.

- Set-B reduced exhaust emissions of CO and UBHC at full load by $40 \%$, while set-C by $60 \%$ when compared with Set-A condition

\section{ACKNOWLEDGMENTS}

Authors thank authorities of Chaitanya Bharathi Institute of Technology, Hyderabad for facilities provided. The financial assistance of Andhra Pradesh Council of Science and Technology (APCOST), Hyderabad is gratefully acknowledged.

\section{REFERENCES}

[1] Usha Madhuri, T., Srinivas, T. and Ramakrishna. A study on automobile exhaust pollution with regard to carbon monoxide emissions. Nature, Env.\& Poll., Tech., 2(4): 2003: 473-474.

[2] Fulekar, M. H. Chemical pollution - a threat to human life. Indian J of Env. Prot., 1(3):1999, pp.353-359.

[3] Khopkar, S.M. Environmental Pollution Analysis. New Age International (P) Ltd, Publishers, New Delhi.2004

[4] Sharma, B.K. Engineering Chemistry, Pragathi Prakashan (P) Ltd., Meerut.2004

[5] Vara Prasad, C.M., Murali Krishna, M.V.S. and Prabhakar Reddy, C. Reductions on 'CO' in petrol engine exhaust using catalytic converter. Proceedings of Fifteenth National Conference on IC Engines and Combustion, College of Engineering, Gindi, Anna University, Chennai, December,1997. 372-377. 
[6] Vara Prasad, C.M., Prabhakar Reddy, C. and Murali Krishna, M.V.S. Investigations on reduction of ' $\mathrm{CO}$ ' in SI engine with catalytic converter. Proceedings of Fourth Asian Pacific International Symposium on Combustion and Energy Utilization, Energy Research Institute, Chulalongkorn University, Bangkok, Thailand, December, II, 1997, pp.576-582

[7] Murali Krishna, M.V.S., Vara Prasad, C.M. and Ramana Reddy, Ch. Studies on control of carbon monoxide emissions in spark ignition engine, using catalytic converter. Ecology, Environment, \& Conservation,6(4),2000, pp.377-380.

[8] Murali Krishna, M.V.S., Ratna Reddy, T. and Vara Prasad, C.M. Investigations on reduction of carbon monoxide from catalytic coated spark ignition engine. Transactions of Environmental Challenges of 21st Century, May,2003, pp.183-194.

[9] Murali Krishna, M.V.S., Kishor, K., Gupta, A.V.S.S.K.S., Reddy, D.N. and Narasimha Kumar, S. Emission characteristics of high speed spark ignition engine with catalytic converter. International Journal of Physical Sciences, 23(3),2009, pp.607-612.

[10] Murali Krishna, M.V.S., Prasad, P.R.K., Ajay Kumar, M., Narayana, M.V. and Balu, M. Parametric studies of catalytic converter on reduction of carbon monoxide in spark ignition engine with gasohol. Engineering Today, V11 (6),2005, pp. 3-7.

[11] Murali Krishna, M.V.S., Kishor, K., Sahithy, A. and Kavya. B.Control of pollutants from copper coated spark ignition engine with gasohol. Indian Journal of Environmental Projection, 26(8),2006, pp.718-723.

[12] Murali Krishna, M.V.S., Kishor, K., Gupta, A.V.S.S.K.S., Narasimha Kumar, S. and Reddy,D.N. Investigations on reduction of carbon monoxide in spark ignition engine with gasohol with catalytic converter. Environment, Ecology and Conservation, 16(3), 2010, pp.389393

[13] Nagini, Y., Murali Krishna, M.V.S. and Naga Sarada, S. Experimental investigations on performance parameters with four stroke spark ignition engine with copper coated combustion chamber with gasohol, International Journal of Current Engineering and Technology, 6(3), 2016, pp. 841-846 Y.Nagini,

[14] Murali Krishna, M.V.S., Naga Sarada, S. and Aditya Seshu,M. Control of aldehydes with four stroke spark ignition engine with copper coated combustion chamber with gasohol with SCR technique, International Journal of Thermal Technologies, 6(2), 2016, pp.134-138.

[15] Indira Priyadarsini, Ch., Murali Krishna, M.V.S., Usha Sri,P. and Aditya Seshu, M. Control of aldehydes with four stroke spark ignition engine fuelled with methanol blended gasoline, International Journal of Current Engineering and Technology, June, 6(3), 2016, pp.825-829.

[16] Indira Priyadarsini, Ch., Murali Krishna, M.V.S., Ipsita Mohanti., Nagini, Y., Narasimha Kumar, S. and Kishor, K. Control of exhaust emissions from copper coated spark ignition engine with butanol blended gasoline with catalytic converter with different catalysts, Pollution Research, 37(4),2018, pp.278-282,

[17] Ipsita Mohanti., Murali Krishna,M. and Ravi Chandra, M. Butanol blend reduces pollutants in spark ignition engine, International Journal of Mechanical and Production Engineering Research and Development,10(2), 2020, pp.1031-1038.

[18] Heywood, J.B. Fundamentals of Internal Combustion Engines, Tata McGraw Hills, New York, 2004 